\title{
Teamwork competence and academic motivation in computer science engineering studies
}

\author{
Jorge E. Pérez Martínez, Javier García Martín
}

\author{
Almudena Sierra Alonso
}

\begin{abstract}
The present work is focused on studying two issues: the "teamwork" generic competence and the "academic motivation". Currently the professional profile of engineers has a strong component of teamwork. On the other hand, motivational profile of students determines their tendencies when they come to work in team, as well as their performance at work. In this context we suggest four hypotheses: (H1) students improve their teamwork capacity by specific training and carrying out a set of activities integrated into an active learning process; (H2) students with higher mastery motivation have better attitude towards team working; (H3) students with higher mastery motivation obtain better results in academic performance; and (H4) students show different motivation profiles in different circumstances: type of courses, teaching methodologies, different times of the learning process. This study was carried out with computer science engineering students from two Spanish universities. The first results point to an improvement in teamwork competence of students if they have previously received specific training in facets of that competence. Other results indicate that there is a correlation between the motivational profiles of students and their perception about teamwork competence. Finally, and contrary to the initial hypothesis, these profiles appear to not influence significantly the academic performance of students.
\end{abstract}

Keywords-Teamwork; academic motivation; generic competences; assessement of competences

\section{INTRODUCTION}

On April 2009, the Ministers responsible for higher education in the 46 countries of the Bologna Process met to establish the priorities for the European Higher Education Area (EHEA) until 2020. They emphasized as well on the significance of student-centred learning and the teaching mission of higher education. 'Student-centred learning requires empowering individual learners, new approaches to teaching and learning, effective support and guidance structures, and a curriculum focused more clearly on the learner in all three cycles' [1].

On the other hand, one of the objectives of the EHEA is helping students to develop generic competences which they will use during their professional practice. Some of them are specific to one degree, but others are considered generic competences and can be achieved in most of the profiles: "planning and time management", "teamwork" or "problem solving" among them. Whilst specific competences can be developed by carrying out different teaching/learning tasks, some of the generic competences need specific training programs to cover skill gaps during the degree. Nowadays each university in the EHEA is defining the level of competences which their graduates must achieve. Every university needs to know the degree in which their graduates have reached that level. Traditional exams and written tests are focused on measuring the level acquired in specific competences, those related to subject contents. But there is less experience in measuring generic competences such as "problem solving" or "teamwork". In this sense there are works that have evaluated the acquisition of generic competences using test and questionnaires with demonstrated psychometric properties [2][4]. Others have assessed these competences using tasks that take into account the different facets inherent to each competence [5]-[7].

This paper is structured as follows: Section 2 presents the hypothesis of this research. Section 3 describes the experiments that have been developed. This way, we will describe the participants who have taken part in the study, the teaching practice used, as well as the measuring instruments used. Section 4 shows the data analysis and the results of this study and Section 5 discusses the interpretation of these results. Finally, in Sections 6 and 7 we present the main conclusions and some limitations of this work.

\section{RESEARCH QUESTIONS}

In the context of higher education, a competence may be understood as the combination of skills, knowledge, attitudes, values and abilities that underpin effective and/or superior performance in a professional area [8]. The EHEA highlights the importance of generic competences in the education process of university students. Among these competences, "teamwork" stands out in the context of engineering education. Consequently students should acquire this competence throughout their academic period, and this should be made in an integrated way in the teaching-learning process, by including activities that improve this skills. Besides, we should have some mechanisms to check if some improvement has been reached in this competence.

On the other hand, as previous studies point out [9], academic motivation has a direct influence on the attitudes and habits of students. For this reason we consider it is necessary to 
analyze student motivation depending on different circumstances (type of course, teaching methodology, different times of the course), as well as its influence on academic performance and on their attitude towards team working.

In this context we suggest four hypotheses: (H1) students improve their teamwork capacity by specific training and carrying out a set of activities integrated into an active learning process; $(\mathrm{H} 2)$ students with higher mastery motivation have better attitude towards team working; (H3) students with higher mastery motivation obtain better results in academic performance; and (H4) students show different motivation profiles in different circumstances: type of courses, teaching methodologies, different times of the learning process.

Three experiments have been conducted in order to confirm or reject these hypotheses. The first one is focused on the first hypotheses. In previous works [10] we studied the improvement of students in "team work" competence measured by mean of the Team Work Behaviour Questionnaire (TWBQ) [11]. The results did not show significant changes in student abilities and we found two reasons that could explain those results. First, a semester may be a very short time between the measures before and after using the methodologies. Second, it is possible that the methodologies alone do not improve the generic competences that we studied. We conclude that students need some specific preparation on "team work" before using them for active learning methodologies. In order to carry out the first experiment we used the same test (TWBQ) to measure the improvement of a group of 20 students throughout one term. Students received specific training in team working and they had to execute some activities directly related to this competence. These activities were supervised by instructor and were integrated into the context of two courses organized by Project Based Learning (PBL) [12]. First results point out significant improvement regarding the teamwork competence.

Hypotheses $\mathrm{H} 2$ and $\mathrm{H} 3$ were analyzed by the second experiment, in which we used the test Achievement Goal Questionnaire (AGQ) [13], [14] in addition to the test TWBQ. AGQ study the different motivational profiles of students. Firstly, we examine the correlation between the motivational profiles of students and their attitude towards teamwork competence, observing a clear relationship. Secondly, correlation between motivational profiles and academic performance is studied, but in this case we did not observed significant influence.

Finally, we conducted the third experiment in order to study the hypotheses H4. In this case we used the test AGQ in different courses of different universities, different years. different type of courses (compulsory and elective), different teaching methodologies and at different times of the term. Differences among academic profiles have been analyzed depending on the different contexts.

\section{METHOD}

\section{A. Participants}

To carry out this study we have taken samples of the following courses:
- Expansion of Software Engineering in the year 2009 (ESE2009).

- Administration of Operating Systems in the year 2009 (AOS2009)

- Operating Systems in the year 2009 (OS2009)

- Operating Systems in the year 2011 (OS2011)

- Students Newly Enrolled in the degree of Software Engineering in the year 2012 (NE2012)

Samples were taken using the two tests mentioned above: TWBQ for teamwork evaluation and AGQ for academic motivation. Data from each course are listed in Table I.

TABLE I. PARTICIPANTS IN THE STUDY

\begin{tabular}{|c|c|c|c|c|}
\hline Course & N & University & Type & year \\
\hline ESE2009 & 44 & URJC & elective & 3 \\
\hline AOS2009 & 52 & UPM & elective & 3 \\
\hline OS2009 & $\begin{array}{c}43 \text { in pre } \\
49 \text { in post }\end{array}$ & UPM & compulsory & 2 \\
\hline OS2011 & 20 & UPM & compulsory & 2 \\
\hline NE2012 & 90 & UPM & & 1 \\
\hline
\end{tabular}

\section{B. Procedure}

Below we briefly describe the educational methodologies that have been used in each subject. ESE2009 used a combination of master lectures along with the development of a programming project (Project Based Learning oriented). AOS2009 followed a traditional teaching, based on lectures and very guided practices in laboratory. OS2009 used Project Based Learning (PBL) along with lectures to support the project development. OS2011 used Cooperative Learning (CL) [15] together with Project Based Learning. In this case a specific training was carried out for the competence of teamwork. This training consisted of a short seminar, planning of the tasks that students had to perform working in team and monitoring of teamwork by the instructor. Finally, in the NE2012 group tests were filled the first day of the course, before teaching the courses of the first semester.

In some cases the samples have been taken at the beginning and at the end of the semester (pre and post), which has allowed to compare the results between to the before and after applying a teaching method during a semester. In other cases only have available an initial sample. In these cases we have been able to study the correlation between the TWQ and AGQ tests within the group and the comparison with other subjects.

\section{Measuring and instruments}

Teamwork was evaluated according to the test Team Work Behaviour Questionnaire (TWBQ). Teamwork behaviour refers to the individual activities which contribute to the team process. Interpersonal behaviours (conflict and problem solving, collaboration, communication) and management behaviours (assuming leadership, establishing goals, planning tasks, coordinating the other members in the group) are assessed. TWBQ has two parts: one in which students have to assess their own ability, TWBQ (Self), and another in which they assess the ability of the group as a whole, TWBQ (Others). In each item (statement), participants have to evaluate 
their own behaviour or the other members' behaviour in terms of an appropriate behaviour, on a 7 points Likert-type scale ( $1=$ not at all; $7=$ very much). The test gives each part a total grade. Although this test is based on self appraisal opinion, research [11] has found that a person's beliefs about teamwork behaviour predict the generic teamwork behaviour that this person displays as a team member. As far as opinion about others is concerned, Tasa [11] explains that "during a team interaction, individuals collect information not only about their own capabilities, but also about other team members' task relevant competences".

Achievement goal was evaluated according the test AGQ. This test supports a $2 \times 2$ achievement goal framework. On the one hand it differentiates between Mastery (goals focused on the development of competence through task mastery) and Performance (goals focused on the demonstration of competence relative to others). On the other hand it observes Approach (goals focused on approaching success) and Avoidance (goals focused on avoiding failure). This way, the 2 x 2 framework produces four types of goal orientations: performance-approach (PeAp), performance-avoidance (PeAv), mastery-approach (MaAp), and mastery-avoidance (MaAv) goals. Three items are chosen to represent each achievement goal following a 7 points Likert sacale $(1=$ not at all for me; $7=$ very true for me).

The statistical techniques used for the analysis were:

- Kolmogorov-Smirnov and Shapiro-Wilk were used to to determine if data can be adequately modelled by a normal distribution.

- t-Student with an $m+n-2$ freedom degree to decide if the equality of the means could be considered in those cases that can be modelled by a normal distribution.

- The equality of the means between the "before" and "after" in those cases that cannot be modelled by a normal distribution was carried out Wilcoxon test for dependent samples.

- Mann-Whitney test was used to contrast independent samples of two different groups.

- Correlation between variables was studied by Pearson correlation coefficient in those cases that follow normal distribution and Rho Spearman when the variables do not follow this distribution.

In particular, for $\mathrm{H} 1$ we run a t-test for dependent variables to decide if the equality of the means could be considered between the "before" and the "after" of TWQ results. This analysis was carried out for ESE2009, OS2009 and OS2011. For the hypothesis H2 Rho Spearman coefficient was used to study the correlation between the different facets of AGQ and TWQ tests. This analysis was made in all groups. The contrast of the H3 hypothesis was carried out using the Rho Spearman coefficient between the different facets of the AGQ test and individual marks obtained in groups AOS2009, OS2009 and OS2011. In the case of NI2012 group we have taken into account the average mark that students have when they come to the University. For hypothesis $\mathrm{H} 4$ several experiments were developed. Firstly, we made a contrast of means between the "before" and "after" of AGQ test using Wilconox test. We could develop this analysis for those groups that had these data (ESE2009, OS2009 and OS2011). Secondly, we compared academic motivation between compulsory and elective courses. In these cases we used the Mann-Whitney test, comparing the AGQ results obtained in ESE2009 (elective) and OS009 (compulsory) one the one hand, and AOS2009 (elective) and OS2009 (compulsory) on the other hand.

Analyses were performed with the SPSS 15.0 statistical Packaged [16].

\section{DATA ANALYSIS AND RESULTS}

\section{A. Exploratory data analysis}

First exploratory analysis of data was carried out in each of the groups. This analysis includes the sample size, the minimum and maximum values, the mean, the variance, as well as Kolmogorov-Smirnov and Shapiro-Wilk tests to check if each of the variables follow the normal distribution.

\section{B. Testing Hypothesis H1}

Table II shows the results of t-Student test obtained from TWBQ from the groups ESE2009, OS2009 and OS2011. Significant results only are obtained in the OS2011 sample, with a value $t=-2.618$ and a $p$-value of 0.017 . With this result we can reject the null hypothesis (equality of means). Due to the low number of students in this group (OS2011), we also used a non-parametric test: the Wilcoxon signed-rank test. We obtained 3 negative ranks, 16 positive and 1 draws in the TWBQ(after) - TWBQ(before) contrast. The statistic had a value $Z=-2.801$ with a significance level of 0.005 . In the other two samples we cannot reject the null hypothesis, since the pvalue exceeds 0,05 .

\section{TABLE II. TWBQ TEST}

\begin{tabular}{|c|c|c|c|c|c|c|}
\hline & Mean & $\begin{array}{c}\text { Standard } \\
\text { Dev. }\end{array}$ & $\begin{array}{c}\mathbf{9 5 \%} \\
\text { Confi- } \\
\text { dence } \\
\text { interval } \\
\text { upper }\end{array}$ & $\begin{array}{c}\mathbf{9 5 \%} \\
\text { Confi- } \\
\text { dence } \\
\text { interval } \\
\text { lower }\end{array}$ & $\mathbf{t}$ & Sig. \\
\hline ESE2009 & $-0,08902$ & 1,23347 & $-0,46402$ & 0,28599 & $-0,479$ & 0,635 \\
\hline OS2009 & 0,00529 & 0,87675 & $-0,26454$ & 0,27511 & 0,040 & 0,969 \\
\hline OS2011 & $-0,44583$ & 0,76150 & $-0,80223$ & $-0,08944$ & $-2,618$ & 0,017 \\
\hline
\end{tabular}

Then we calculate the effect size for the three courses. We use the formula for samples related with pre- and post-tests without control group; in other words, we obtain the ratio between the mean difference (post - pre) and the standard deviation in post. For ESE2009 and OS2009, we obtain a value of $\mathrm{d}$ much lower than 0.2 , that according to [17] is not significant. For OS2011, d has the value of 0.4049 which is a moderate value. This indicates that there has been a significant advance in the ability to work in team in the individuals of the course OS2011. This is undoubtedly due to the specific training that students received in this subject.

\section{Testing Hypothesys $\mathrm{H} 2$}

For this hypothesis we have taken into account only the Mastery Approach (MaAp) variable of the AGQ test. Table III shows the Spearman correlation coefficient for the ESE2009 course with a $95 \%$ confidence interval. We observe that 
significant results are obtained regarding the correlation of the team working at the end of the semester (SET_END) and motivation Mastery Approach, both at the beginning and at the end of the semester.

TABLE III. SPEARMAN CORRELATION FOR ESE2009

\begin{tabular}{|c|c|c|c|}
\hline & & ESE & \\
\hline & & AQ_MaAp_INI & $A Q$ MaAp_END \\
\hline SET_INI & $\begin{array}{l}\text { Correlation } \\
\text { coefficient }\end{array}$ & 0,144 & $-0,062$ \\
\hline & $\begin{array}{l}\text { Significance } \\
\text { (unilateral) }\end{array}$ & 0,176 & 0,343 \\
\hline & $\mathrm{N}$ & 44 & 44 \\
\hline SET_END & $\begin{array}{l}\text { Correlation } \\
\text { coefficient }\end{array}$ & $0,252\left(^{*}\right)$ & $0,299\left(^{*}\right)$ \\
\hline & $\begin{array}{l}\text { Significance } \\
\text { (unilateral) }\end{array}$ & 0,049 & 0,024 \\
\hline & $\mathrm{N}$ & 44 & 44 \\
\hline
\end{tabular}

In the Group AOS2009 Spearman Rho coefficient analysis has been calculated, obtaining a significant correlation between SET INI and MaAp variables with a $1 \%$ confidence level. In the OS2009 group, we observed a significant positive correlation at the 0.01 level between the TWBQ and the Mastery Approach motivation, both at the beginning and at the end of the semester. In the Group OS2011 there is a positive correlation with a significance level of 0.05 between the TWBQ and the Mastery Approach motivation, both at the beginning and at the end of the semester. In the NI2012 group, once again, we observed a significant correlation between the TWBQ and the Mastery Approach motivation with a 0.01 level.

\section{Testing Hypothesis H3}

In order to study the correlation between motivation and academic performance, we have calculated the Rho Spearman coefficient (Table IV). In this case, in addition to the MaAp variable we have included PeAv (Performance Avoidance), since we have obtained significant results which can provide explanations to the hypothesis. For groups AOS2009, OS2009 and OS2011 we took into account the individual mark (we excluded those marks obtained from group work) obtained in the semester. In the case of the group of students newly enrolled (NE2012) we choose the mark that students have to enter the University.

TABLE IV. SPEARMAN CORRELATION FOR H3

\begin{tabular}{|c|c|r|r|r|r|}
\hline & \multicolumn{1}{|c|}{$\begin{array}{c}\text { OOS2009 } \\
\text { Marks }\end{array}$} & \multicolumn{1}{c|}{$\begin{array}{c}\text { OS2009 } \\
\text { Marks }\end{array}$} & \multicolumn{1}{c|}{$\begin{array}{c}\text { OS2011 } \\
\text { Marks }\end{array}$} & \multicolumn{1}{c|}{$\begin{array}{c}\text { NE2012 } \\
\text { Marks }\end{array}$} \\
\hline $\begin{array}{c}\text { AQ_ } \\
\text { PeAv_ } \\
\text { INI }\end{array}$ & $\begin{array}{c}\text { Correlation } \\
\text { coefficient }\end{array}$ & $-0,288\left(^{*}\right)$ & 0,024 & $-0,260$ & $-0,26\left(^{* *}\right)$ \\
\cline { 2 - 6 } & $\begin{array}{c}\text { Significance } \\
\text { (unilateral) }\end{array}$ & 0,026 & 0,442 & 0,128 & 0,008 \\
\cline { 2 - 6 } & $\mathrm{N}$ & 46 & 40 & 20 & 80 \\
\hline \multirow{2}{*}{$\begin{array}{c}\mathbf{A Q} \\
\text { MaAp_ } \\
\text { INI }\end{array}$} & $\begin{array}{c}\text { Correlation } \\
\text { coefficient }\end{array}$ & $-0,096$ & $-0,332(*)$ & 0,125 & $-0,005$ \\
\cline { 2 - 6 } & $\begin{array}{c}\text { Significance } \\
\text { (unilateral) }\end{array}$ & 0,262 & 0,018 & 0,466 & 0,481 \\
\cline { 2 - 6 } & $\mathrm{N}$ & 46 & 40 & 20 & 80 \\
\hline
\end{tabular}

* Significance level 0,05 ** Significance level 0,01 .

As far as MaAp is concerned, we detect only correlation in the OS2009 group. In addition, this correlation is negative, what does not make much sense, because it would mean that the greater motivation students have the worse academic results are obtained. On the other hand, the variable PeAv offers negative correlation in two cases with significance level 0.05 and 0.01 . This result makes more sense, since they indicate that students with greater fear of failure get worse results.

\section{E. Testing Hypothesis $\mathrm{H4}$}

First of all, we have studied the difference in motivation between the beginning and the end of the semester in IS2009, SO2009, and SO2011 groups. In all three cases, we have used the Wilcoxon signed-rank test, since the MaAp variable does not follow the normal distribution. Table $\mathrm{V}$ shows the rank test for ESE2009 group, in which we obtained 23 negative ranks, 14 positive and 7 draws in the MaAp_END - MaAp_INI contrast.

TABLE V. WILCOXON SIGNED-RANK TEST

\begin{tabular}{|c|c|c|c|c|}
\hline & ESE2009 & $\mathbf{N}$ & $\begin{array}{c}\text { Average } \\
\text { rank }\end{array}$ & Rank sum \\
\hline \multirow[t]{4}{*}{$\begin{array}{l}\text { AQ_MaAp_END } \\
-\mathbf{A Q} \text { MaAp_INI } \\
\end{array}$} & Negative ranks & $23(\mathrm{a})$ & 22,89 & 526,50 \\
\hline & Positive ranks & $14(\mathrm{~b})$ & 12,61 & 176,50 \\
\hline & Draws & $7(\mathrm{c})$ & & \\
\hline & Total & 44 & & \\
\hline \multirow[t]{4}{*}{$\begin{array}{l}\text { AQ_PeAv_END } \\
-\mathbf{A Q} \mathbf{P e A v} \text { INI }\end{array}$} & Negative ranks & $17(d)$ & 15,44 & 262,50 \\
\hline & Positive ranks & 22(e) & 23,52 & 517,50 \\
\hline & Draws & $5(f)$ & & \\
\hline & Total & 44 & & \\
\hline \multicolumn{5}{|c|}{ 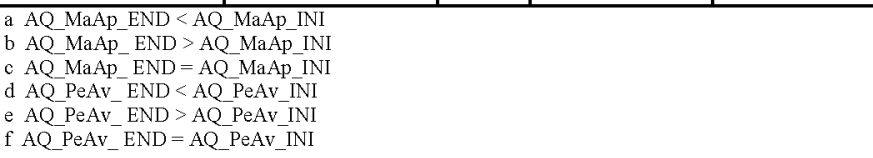 } \\
\hline
\end{tabular}

The statistic $Z$ (Table VI) has a value of -2.646 with a significance level of 0.008 . These results indicate that the MaAp motivation at the end of the semester is significantly lower than at the beginning in the ESE2009 group. We calculate the effect size for this case obtaining a value of $d$ equal to 0.439 , which according to [17] is a moderate value. In the case of the groups OS2009 and OS2011 no significant differences were obtained.

TABLE VI. STATISTICAL CONTRAST

\begin{tabular}{|c|c|c|c|}
\hline & $\begin{array}{c}\text { ESE2009 } \\
\text { AQ_MaAp_END } \\
-\mathbf{A Q} \mathbf{M a A p} I N I\end{array}$ & $\begin{array}{c}\text { OS2009 } \\
\text { AQ_MaAp_END } \\
-\mathbf{A Q} \text { MaAp_INI }\end{array}$ & $\begin{array}{c}\text { OS2011 } \\
\text { AQ_MaAp_END_MaAp_INI }\end{array}$ \\
\hline$Z$ & $-2,646(\mathbf{a})$ &,$- 621(\mathrm{a})$ &,$- 469(\mathrm{a})$ \\
\hline $\begin{array}{c}\text { Significance } \\
\text { (bilateral) }\end{array}$ &, 008 &, 534 &, 639 \\
\hline
\end{tabular}


Secondly we have compared the academic motivation between elective and compulsory courses. For this purpose we have used Mann-Whitney test for ESE2009 against OS2009 groups and AOS2009 against OS2009. In any case we find significant differences in the variable MaAp. However, a significant difference in $\mathrm{PaAp}$ is observed in both comparisons and for comparison of ASO2019 against SO2009 there is also a significant difference in PeAv. Specifically, in the case of AOS2009 against OS2009, PeAv and PeAp have higher values in the compulsory subject than in the elective one. $\mathrm{PeAv}$ is also higher in the compulsory course OS2009 than in the elective course ESE2009. Table VII shows this statistical contrast.

TABLE VII. STATISTICAL CONTRAST

\begin{tabular}{|c|c|c|c|c|c|}
\hline & & $\begin{array}{c}\text { AQ } \\
\text { PeAp } \\
\text { END }\end{array}$ & $\begin{array}{c}\text { AQ } \\
\text { PeAv } \\
\text { END }\end{array}$ & $\begin{array}{c}\text { AQ } \\
\text { MaAv } \\
\text { END }\end{array}$ & $\begin{array}{c}\mathrm{AQ} \\
\mathrm{MaAp} \\
\text { END }\end{array}$ \\
\hline \multirow{4}{*}{$\begin{array}{c}\text { ESE2009 } \\
\text { Vs. } \\
\text { OS2009 }\end{array}$} & $\begin{array}{c}\text { U of Mann- } \\
\text { Whitney }\end{array}$ & 814 & 832 & 844 & 905 \\
\hline & $\begin{array}{c}\text { W de } \\
\text { Wilcoxon }\end{array}$ & 1804 & 1822 & 1834 & 1895 \\
\hline & $Z$ & $-2,03$ & $-1,897$ & $-1,805$ & $-1,339$ \\
\hline & $\begin{array}{c}\text { Significance } \\
\text { (bilateral) }\end{array}$ & 0,042 & 0,058 & 0,071 & 0,181 \\
\hline \multirow{4}{*}{$\begin{array}{c}\text { AOS2009 } \\
\text { Vs. } \\
\text { OS2009 }\end{array}$} & $\begin{array}{l}\text { U of Mann- } \\
\text { Whitney }\end{array}$ & 737,5 & 689 & 1239,5 & 1112 \\
\hline & $\begin{array}{c}\text { W de } \\
\text { Wilcoxon }\end{array}$ & 2115 & 2067 & 2617,5 & 2337 \\
\hline & $Z$ & $-3,65$ & $-3,984$ & $-0,235$ & $-1,111$ \\
\hline & $\begin{array}{l}\text { Significance } \\
\text { (bilateral) }\end{array}$ & 0 & 0 & 0,814 & 0,267 \\
\hline
\end{tabular}

We then calculate the effect size in those cases in which there is a significant difference between the arithmetic means. We use a standard deviation combined, since the samples are independent (different subjects in each sample) and we do not have control group. To do this, we used the formula of Cohen [17] which takes into account the variances, as described in (1).

$$
\mathrm{d}=\frac{\overline{\mathrm{X}}_{1}-\overline{\mathrm{X}}_{2}}{\sigma} ; \sigma=\sqrt{\frac{\left(\mathrm{N}_{1}\right) \sigma_{\mathrm{R}(1)}^{2}+\left(\mathrm{N}_{2}\right) \sigma_{\mathrm{R}(2)}^{2}}{\mathrm{~N}_{1}+\mathrm{N}_{2}}}
$$

For the variable AQ_PeAp we compared ESE2009 against OS2009 and AOS2009 against OS2009 courses. Table VIII shows the most interesting data for the calculation of the effect size of the three courses.

TABLE VIII. DATA TO CALCULATE THE EFFECT SIZE ABOUT AQ PEAP_END VARIABLE

\begin{tabular}{|l|c|c|c|}
\hline AQ_PeAp_END & Mean & variance & N \\
\hline OS2009 & 4.2882 & 2.2468 & 43 \\
\hline ESE2009 & 3.5076 & 3.2273 & 44 \\
\hline AOS2009 & 3.0545 & 2.3786 & 52 \\
\hline
\end{tabular}

The value of effect size is indicated in Table IX. As we can see, the difference is greater in the case of AOS2009-OS2009. In this case an average individual of OS2009 is more motivated to get a good result that $84 \%$ of individuals in the course AOS2009.

TABLE IX. EFFECT SIZE ABOUT AQ_PEAP_END VARIABLE

\begin{tabular}{|c|c|}
\hline Courses /effect size & d \\
\hline ESE2009 vs. OS2009 & 0.443 \\
\hline AOS2009 vs. OS2009 & 1.015 \\
\hline
\end{tabular}

For the variable AQ PeAv we compare the course AOS2009 against OS2009. Table $X$ shows the most interesting data for the calculation of the size effect.

TABLE X. DATA TO CALCULATE THE EFFECT SIZE ABOUT AQ PEAV_END VARIABLE

\begin{tabular}{|l|c|c|c|}
\hline AQ_PeAv_END & Mean & variance & N \\
\hline OS2009 & 4.7287 & 2.9114 & 43 \\
\hline AOS2009 & 3.1026 & 2.1069 & 52 \\
\hline
\end{tabular}

The value of $d$ is 1.034 , which is very significant. As in the case of the AQ_PeAp variable, this result indicates that an average individual of OS2009 is more motivated by the fear of failure that $84 \%$ of the students of the course AOS2009.

\section{DISCUSSION}

The hypothesis Hl is confirmed: "students improve their teamwork capacity by specific training and carrying out a set of activities into an integrated active learning process". Among the three subjects analyzed, we perceived improvement in the teamwork competence only in OS2011. This is precisely the course where students were trained in this competence. We should also highlight that, despite having a small sample (20 students), we have detected a difference between the pre and post measures. This difference is confirmed with the calculation of the effect size that has a value of 0.4049 . In the case of academic performance or educational research, usually a value of significance equal to 0.5 is considered, even quite minor values (around 0.3).

The hypothesis $\mathrm{H} 2$ is also confirmed: 'students with higher mastery motivation have better attitude towards team working'. As we have shown in the analysis, there is a positive correlation between motivation for learning and teamwork competence in all analyzed courses: ESE2009, AOS2009, OS2009, OS011 and NE2012.

Regarding the hypothesis $\mathrm{H} 3$, we can only confirm that students with greater fear of failure get worse academic performance. However, we have found a counter hypothesis in the course OS2009. In this sense, the correlation is reverse: greater interest in learning is correlated to worse academic results. We don't have data that may explain this case. The course took place normally in a PBL environment. The only possible explanation is based on considered qualifications to explain academic achievement: only individual notes and not those of the group. It may be that the marks of the group hide the individual mark of some members of the same group.

As far as hypothesis $\mathrm{H} 4$ is concerned: "students show different motivation profiles in different circumstances: type of courses, teaching methodologies, different times of the 
learning process" we have analyzed the motivation according to the type of subject (compulsory vs. elective). It has also been analyzed the difference in motivation between the beginning and the end of the semester. Although the results do not confirm the hypothesis, there are indications that in the compulsory courses students have: (a) greater fear of failure; (b) greater motivation for academic success.

\section{CONCLUSIONS}

In this work, several aspects of the academic motivation of students have been studied according to the facets listed in the test AGQ. We have also studied the perception that students have about their teamwork competence, using the TWBQ test for this study.

One of the first conclusions of this study suggests that students improve their teamwork competence if they receive specific training in areas related to this competence. It is not enough for students to work in group to acquire them alone this competence. It is necessary to schedule training on leadership, conflict management, planning, etc. In addition, it is necessary to program activities, within the course, that help to develop this competence. These activities should target not only the specific matter of the course, but also learning some of the facets of teamwork competence. In addition, as it has been shown, the teamwork competence is enhanced if the student has motivation for learning.

We can also conclude that motivation for results is higher in compulsory courses than in elective courses. This motivation has a double perspective: improve the academic performance and avoid failure. However, we have not detected higher motivation for learning (mastery).

Finally, this study suggests a counter hypothesis that we have to study in more depth. It seems illogical that the greater the interest in learning, the worse academic results. Surely, some variables that we have not taken into account in the study influence the results. Moreover, this result is given in a single group.

\section{LIMITATION OF THE WORK}

The limited number of participants may have influenced the results. In further years, a higher number of students will follow this subject. This way, a deeper analysis will be possible.

\section{REFERENCES}

[1] Bologna Process. Leuven/Louvain-la-Neuve Communique'. The Bologna process 2020-The European Higher Education Area in the new decade. [Online]. Available: http://www.ehea.info/articledetails. aspx?ArticleId $=43$

[2] Pérez Martínez, J.E., García, J., Muñoz, I. and Sierra Alonso, A., "Active Learning and Generic Competences in an Operating Systems Course," International Journal of Engineering Education, vol. 26, no. 6, pp. 1484-1492, Dec. 2010.

[3] García, J., Manzano, P., Pérez, J.E., Rodríguez, F. and Alcover, C.M., "Measuring the influence of active learning (CL and PBL) in students' generics competences," in Int. Conf., Visions, challenges and strategies for problem based learning, Aalborg, Denmark, 2010.

[4] García, J. and Pérez, J.E., "Measuring the influence of cooperative learning and Project based learning on problem solving skill," in Research in Engineering Education Symp., Madrid, Spain, 2011.

[5] Pérez Martínez, J.E., Blanco Viejo, G., Tovar Caro, E., Arquero Hidalgo, A., Vizcarro Guarch, C. and Borges Grün, T., "Assessment of transferable competences in computing," in Research in Engineering Education Symp., Madrid, Spain, 2011.

[6] Vizcarro Guarch, C., Pérez, J.E., Martin Espinosa, P., Tovar, E., Blanco, G., Arquero, A. and García Martín, J., "Assessment of learning outcomes in computing studies," in IEEE Educon 2013, Berlin, Germany.

[7] Vizcarro Guarch, C., Pérez, J.E., Martín Espinosa, P., Tovar, E., Blanco, G., Cobos, R., Bermúdez Marín, A. and Ruíz Gallardo, J.R. "Assessment of problem solving in computing studies," in 2013 Frontiers in Education Conf., Oklahoma City, Oklahoma.

[8] European Communities, "ECTS Users'Guide," Available: http://ec.europa.eu/education/lifelong-learning-policy/ects en.htm.

[9] Ainley M.D.. "Styles of engagement with learning: Multidimensional assessment of their relationship with strategy use and school achievement," Journal of Educational Psychology, vol. 85, no. 3, pp. 395-405, Sept. 1993.

[10] García, J., Pérez Martínez, J.E., Rodríguez F. \& Alcover, C.M., "Measuring the influence of active learning - cooperative learning and project-based learning - in two types of students'generic competences," in Visions, Challenges, and Strategies: PBL Principles and Methodologies in a Danish and Global Perspective, L. Krogh \& A.A. Jensen, Eds. Aalborg: Aalborg University Press, 2013, pp. 281-297.

[11] Tasa K., Taggar S. and Seijts G.H., "The development of collective efficacy in teams: A multi-level and longitudinal perspective," Journal of Applied Psychology, vol. 92, no. 1, pp. 17-27, Jan. 2007

[12] Graaff, E. D., and Kolmos, A., "Characteristics of problem-based learning," International Journal of Engineering Education, vol. 19, no. 5, pp. 657-662, Sep. 2003.

[13] Elliot A.J., McGregor H.A., "A 2 X 2 Achievent goal framework," Journal of Personality and Social Psychology, vol. 80, No 3, pp. 501519, Mar. 2001

[14] Elliot, A. J., and Murayama, K., "On the measurement of achievement goals: critique, illustration, and application," Journal of Educational Psychology, vol. 100, no. 3, pp. 613-628, Aug. 2008.

[15] D. W. Johnson, R. T. Johnson and K. A. Smith, Active learning: Cooperation in the college classroom, $2^{\text {nd }}$ ed., Edina, MN: Interaction Book Co., 1998.

[16] IBM SPSS, SPSS 15.0, SPSS Inc, Chicago, IL., 2006.

[17] Cohen, J., "A power primer," Psychological Buletin, vol. 112, no. I, pp. 155-159, Jul. 1992. 